\title{
Relationship Between Motivation-enhancing HR Practices and Customer Satisfaction: The Mediating Role of Emotional Intelligence
}

${ }^{a}$ MSarah Azhar, ${ }^{b}$ Farhan Sarwar, ${ }^{c}$ Shoukat Ali

${ }^{a}$ Assistant Professor. Department of Economics and Business Administration, University of Education, Township Campus, Lahore, Pakistan

Email: sarahazhar@hotmail.com

${ }^{\mathrm{b}}$ Assistant Professor, Department of Economics and Business Administration, University of Education, Township Campus, Lahore, Pakistan

Email: farhansarwar@ue.edu.pk

${ }^{\mathrm{c}}$ Lecturer, Department of Commerce, The Islamia University of Bahawalpur, Pakistan

Email: shoukat.ali@iub.edu.pk

\begin{tabular}{|c|c|}
\hline ARTICLE DETAILS & ABSTRACT \\
\hline History: & \multirow{8}{*}{$\begin{array}{l}\text { This study describes and expounds link between motivation-enhancing } \\
\text { HR practices (M-HRM) and customer satisfaction (CS). Motivation- } \\
\text { enhancing HR practices include compensation \& incentive (CI) and } \\
\text { performance management (PM).The mediation of emotional intelligence } \\
\text { (EI) is verified between the M-HRM and CS. The research was directed } \\
\text { on } 126 \text { bank branches operational in Punjab (Pakistan) with } 467 \text { banking } \\
\text { employees and } 934 \text { customers. The process of statistical analysis was } \\
\text { performed by Structural equation modeling (SEM). A substantial } \\
\text { relationship amongst all the variables of study (i.e. M-HRM, EI and CS) } \\
\text { was established. It was clinched resultantly, that M-HRM exert impact } \\
\text { on CS, through EI in direct as well as indirect ways. }\end{array}$} \\
\hline Accepted 28 April 2021 & \\
\hline Available Online June 2021 & \\
\hline Keywords: & \\
\hline & \\
\hline Incentive, Performance & \\
\hline Management & \\
\hline $\begin{array}{l}\text { JEL Classification: } \\
\text { J28, J29 }\end{array}$ & \\
\hline DOI: $10.47067 /$ real.v4i2.155 & $\begin{array}{l}\text { (C) } 2021 \text { The authors. Published by SPCRD Global Publishing. This is an } \\
\text { open access article under the Creative Commons Attribution- } \\
\text { NonCommercial } 4.0\end{array}$ \\
\hline
\end{tabular}

Corresponding author's email address: sarahazhar@hotmail.com

\section{Introduction}

In a competitive milieu, the custody of customer central doctrines for a prosperous industry (Colgate \& Danaher, 2000).Service industry is growing endlessly at the same time (Henderson, 2012), and achieving exceptional customer's service is a challenge (Liao \& Chuang, 2007). Hence, because of its fast and continual growth, the scope and the economic potential of this sector have not yet been researched extensively (Wamboye \& Nyaronga, 2018).

For this, with the passage of time, literature has focused to identify the different kinds of services relationships (Gutek, 1995) which would demonstrate outcomes of relationship marketing and would also help to comprehend the reasons for involving the consumers in service relationships 
(Gwinner, Gremler, \& Bitner, 1998). The relationships, according to service sector studies, develop through recurring encounters with an organization (Voorhees, Fombelle, Allen, Bone, \& Aach, 2014). In recent times top management has widen the scope of their action plans to develop and maintain the procedure to deal with the customers to make their experience better (Lemon \&Verhoef, 2016). These repeated encounters help to make assessment about quality of service of a firm which ultimately plays a vital role on customers' satisfaction over the quality of firm as well as their intention to carry on the relationship (Bitner\&Wang, 2014).

Conversely a tributary of services linkage work (Wiley, 1996) is revealed which has examined relationship of internal management mechanism of service organizations and outside customers' outcome (Liao \& Chuang, 2004). Foundation of such stream of literature was that front line employees, no doubt, contribute the vital part in introducing how organization functions in a desired manner of customer outcomes.

Front-line employees of service organizations representing the agenda of organizations play a vital role in service encounters involving dynamic interaction between consumers and the workers (Solomon, Suprenant, Czepiel, \& Gutman, 1985).Empirically tested research reflects that higher the individuals are capable to offer high-standard services; the more consumers are expected to show positive assessment of services interaction, enjoy greater satisfaction which resultantly enhance the buying and also possibility of next visit (Borucki \& Burke, 1999). So for these reason it is necessary to know that what would predict the employees' service functioning.

For the better understanding of those causes which impact emotional performance, the variable of 'emotional labor 'was considered by many researchers. The literature on emotional labor validates that emotional intelligence is the firm forecaster of emotional performance (Joseph \& Newman, 2010) and customer satisfaction (Giardini \& Frese, 2006).

Organizations might effect emotional labor through HR practices (Pugh, Diefendorff, \& Moran, 2013). Pugh et al. (2013) has studied the available work in admiration of the impact of HR on emotional labor, but research also reveals that majority of work is quantitative in nature (Poster, 2011).According to Jiang, Lepak, Han, et al. (2012) researches in area of HRM suggested concentrating on HR practices in bundles as an alternative of distinct practices while examining the influence of HR system upon the individual and organizational performance.

The purpose of this research is to define the association amongst the motivation-enhancing HR practices (compensation \& incentives, performance management), emotional intelligence and customer satisfaction. Theoretical framework is portrayed in Fig 1. It shows motivation-enhancing HR practices are related to customer satisfaction. Though, motivation-enhancing HR practices are inadequate determining factor of customer satisfaction. Hereafter, it was proposed that emotional intelligence worked as mediating variable between motivation-enhancing HR practices and customer satisfaction.

Finally, this study pays to the thoughtfulness of the way these constructs are related to segment of bank industry in Pakistan. The empirical results that banking industry is overlooking a trial to accomplish customer satisfaction is the reason for selecting this sector for research (Khan \& Fasih, ,2014; Naeem, Akram \& Saif 2011). The service sector has a huge proportion of local and global employment, too. Hence, because of its fast and continual growth, the scope and the economic potential of this sector have not yet been researched extensively (Wamboye \& Nyaronga, 2018). In Pakistan, the 
policies of professional recruitment, merit based promotion, need based trainings and result oriented appraisals are still not fully established which needs improvement along with introducing the true concept of organizational justice (Kazi 2003; Islam 2005) is the rational to conduct this research in banking sector of Pakistan. Provided this it is noticeable that western model of conceptual framework is going to be tested in Pakistani culture keeping in view the distinguishing expansion of HRM practices in this background.

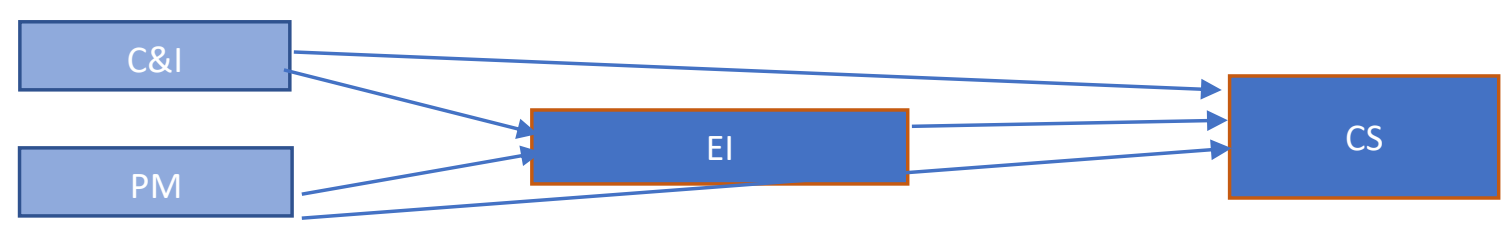

Fig 1: Theoretical Framework

\section{Literature Review}

\subsection{Motivation-enhancing HR practices}

Human resource practices are the dominant revenues which can affect the skills and behaviors of employees in the organizations for attaining organizational objectives (Chen \& Huang, 2009).Three HR policies domain include ability and skill HR domain, motivation \& effort HR domain, and opportunities to contribute the HR domain.

The motivation and efforts HR policies domain consist of HR practices which intend to affect the employees' motivation and struggle instead of their abilities while performing at workplace. In this domain, directly instrumental general HR policies are performance management policies, compensation \& incentive policies.

\subsection{Emotional intelligence}

The measure of emotions in service connections are addressed by tributaries of emotional labor (Hochschild 1983). Mainstream models of emotional labor include emotional display rules, emotion regulation, and emotional displays (Grandey \& Gabriel, 2015).

\subsection{Customer satisfaction}

Usually, the variable of satisfaction was clarified as a state of mind, which is affected by perceptive pioneers (Bigné, Andreu, \& Gnoth, 2005).According to Hunt, 1993 satisfaction is keen valuation of understanding of emotions.

\subsection{Relationship between motivation-enhancing HR practices and emotional intelligence}

As per Jiang, Lepak, Han, et al. (2012) performance management and compensation \& incentive systems are well considered to increase employees' motivation at work .Motivation-enhancing practices of HR seem extrinsic in features as compare to the practices of opportunity-enhancing (Jiang, Lepak, Han, et al., 2012). However, monitoring is a positive predictor of employee well-being irrespective of the fact that monitoring focused only the development objectives or merely the evaluation of general working (Holman, Chissek, \& Totterdell, 2002). Another view was that employees perceiving strong monitoring would affect negatively the personal development of workers in the organization (Holman et al., 2002). Admittedly it has been proved through research that performance management system is 
related with emotional labor, yet further investigation is required to find out possibility of its positive effect upon emotional performance.

The compensation systems are under discussion for jobs requiring emotional performance since the work of Hochschild's (1983) .In growing service industry expertise of emotional labor are considerably valuable so it can make it possible to ensure achievement of goals of emotional labor, hence such expertise become a criteria for enhanced incentives (Glomb, Kammeyer-Mueller, \& Rotundo,2004)). However, Diefendorff and Croyle (2008) stated that compensation for performing emotional labor goals was antecedent of dedication and motivation of employees to take the display rules of organizations. It was also suggested by Grandey, Chi, et al. (2013) that monetary compensation was found as safeguard for workers against pressures of emotional demands.

Upon the foundation of this literature and arguments it can be certainly presumed that motivation-enhancing HR practices (compensation \& incentive, performance management) are linked with the emotional intelligence:

H1a: There is a significant relationship between compensation \& incentive and emotional intelligence of employees.

$\mathrm{H} 1 \mathrm{~b}$ : There is a significant relationship between performance management and emotional intelligence of employees.

\subsection{Relationship between emotional intelligence and customer satisfaction}

Emotional intelligence is a strong forecaster of emotional performance (Joseph \& Newman, 2010) and customer satisfaction (Giardini \& Frese, 2006). Conventionally when the emotional display is more, the more will be customer satisfaction as well as return intentions of customer (Barger \& Grandey 2006).Somatic signals like annotations with eyes, a smile on face and lenient pitch, all are the of positive displays, having influences on customers (Gabriel, Acosta, et al.2015). On the basis of above literature it can be hypothesized as:

$\mathrm{H} 2$ : There is a significant relationship between emotional intelligence and customer satisfaction.

\subsection{Relationship between motivation-enhancing HR practices and customer satisfaction}

Once the employees perceive HR practices to offer fairly by the management they naturally feel dedicated while putting their best into exercise in terms of both their energy and resources for developing an effective dealing with the customers (Ulrich, Halbrook, Meder, Stuchlik, \& Thorpe 1991).Similarly Zerbe, Dobni, and Harel (1998) noted that perceptions of organizational employees about HRM practices' was directly related with their service behavior .Some studies did show that performance appraisal provoke the employees' performance being consistent with expectations of customers consequently to ensure customer satisfaction (Hartline, Maxham \& McKee, 200o). Following hypothesis are made on the basis of above literature:

H3a: There is a significant relationship between compensation \& incentive and customer satisfaction. $\mathrm{H} 3 \mathrm{~b}$ : There is a significant relationship between performance management and customer satisfaction.

\subsection{Mediating role of emotional intelligence}

Pugh, Diefendorff, and Moran (2013) have recommended an approach to reach emotional labor through applying the HR practices, for example employees can be trained in a the way so that they can show emotional behavior and anticipated inducements for clienteles in a appropriate means so emotional performance can be slightly satisfied. Despite of the fact that theory of combined HR practices is not fully developed, earlier inquiries have concluded that emotional performance is 
connected with customer satisfaction (Gabriel, Acosta, \& Grandey, 2015). Chen and Lin,20o9 proved that HR policies may help employees who are emotionally worn-out,. Therefore it is hypothesized as:

H4a: Emotional intelligence mediates the relationship between compensation \& incentives and customer satisfaction.

H4b: Emotional intelligence mediates the relationship between performance management and customer satisfaction.

\section{Research Methodology}

\subsection{Participants and procedure}

This study was conducted in the banking segment of province Punjab. This research was led incognito on 467 employees from banks and 934 customers. There were total of 126 of bank branches functioning in nine divisions of Punjab. At first stage 126 branches of selected banks from all o9 administrative divisions of the province of Punjab (i.e. Rawalpindi, Lahore, Faisalabad, Multan, Bahawalpur, Sargodha, DG khan, Sahiwal and Gujranwala divisions) were selected for this study for collection of data. At second stage, from the total number of 126 branches in og divisions of province of the Punjab, a random sample of branches was drawn from each area to represent proportionate participation of branches from all over the Province. From these designated bank branches there was a random selection of employees. The intended sample of this study was 467 individuals/employees of the banks.

Unit of Analysis is dyad (banking employees \& customer) in banking sector. The process run to a total of 467 dyadic cases containing bank employee and two related customer responses. Later on for data analysis the two customer reactions were averaged, as per the literature (Deshpandé, Farley, and Webster 1993).

Questionnaires were set to employees in the bank branches. The language of questionnaire was English. Translational equivalence was established by the process of translation and back translation. Statistical analyses were completed with the help of SPSS software, version 21. PLS-SEM technique is known as an advance shape of structural equation modeling (Wold, 1982). This latest technique is effective for those structural equation models that contain number of dormant factors (Gustafsson \& Johnson, 2004). This technique is elastic so considered as a better approach to construct a statistical model notwithstanding the ability of forecasting (Ringle et al., 2005). It is an established fact that PLSSEM has more capability to compute error for producing a précised measurement of effects of mediation (Chin, 1998).

\subsection{Measures}

Following variables were considered in this study.

\subsubsection{Motivation-enhancing HR practices}

This includes a scale on compensation \& incentives and performance management.

\subsubsection{Compensation \& incentive}

There are total of 4 item in this scale. The items have been embraced from the study of Wei, Han \& Hsu (2010). Sample items included "Our organization has a competency-based pay system

\subsubsection{Performance management}

A 12 item scale measured this construct. The items are approved from Sharma, Sharma, \& Agarwal, 2016. Higher scores reflected positive perceptions about performance management in the bank employees. 


\subsubsection{Emotional intelligence}

A 16 item scale measured this variable. These items are taken from the scale of Emotional Intelligence by Law et al., 2004

\subsubsection{Customer satisfaction}

A 3 -item scale measured this variable. The items are taken from Maxham and Netemeyer 2002. "I am satisfied with my overall experience with this bank" is a sample item.

\section{Results}

\subsection{Assessment of Measurement Model (Stage One)}

The measurement model is defined as "an SEM model that (a) specifies the indicators for each construct and (b) enable an assessment of construct validity” (Hair et al.,2010).

Factor analysis was conducted to determine the factor configuration for the items for HR practices, emotional intelligence and customer satisfaction. Using PLS path model hypotheses were tested. The loadings of all indicators were reviewed and found that all the outer loadings were bigger than 0.4(Churchill ,1979).The AVE value for all concepts is bigger than 0.50, and composite reliability is bigger than 0.7 , in this way convergent validity of variables has been proven.

Table 1: CFA (Confirmatory Factor Analysis)

\begin{tabular}{|c|c|c|c|c|c|}
\hline $\begin{array}{r}\text { Constructs } \\
\end{array}$ & Items & Loadings & Alpha & CR & AVE \\
\hline \multirow[t]{6}{*}{ Compensation \& incentive } & & & 0.811 & 0.868 & 0.568 \\
\hline & CI1 & 0.765 & & & \\
\hline & CI2 & 0.752 & & & \\
\hline & $\mathrm{CI}_{3}$ & 0.771 & & & \\
\hline & $\mathrm{CI}_{4}$ & 0.743 & & & \\
\hline & $\mathrm{CI}_{5}$ & 0.736 & & & \\
\hline \multirow[t]{13}{*}{ Performance management } & & & 0.926 & 0.936 & 0.551 \\
\hline & PM1 & 0.712 & & & \\
\hline & PM10 & 0.748 & & & \\
\hline & PM11 & 0.756 & & & \\
\hline & PM12 & 0.781 & & & \\
\hline & PM2 & 0.709 & & & \\
\hline & PM3 & 0.691 & & & \\
\hline & $\mathrm{PM}_{4}$ & 0.76 & & & \\
\hline & $\mathrm{PM}_{5}$ & 0.741 & & & \\
\hline & PM6 & 0.695 & & & \\
\hline & $\mathrm{PM}_{7}$ & 0.777 & & & \\
\hline & PM8 & 0.768 & & & \\
\hline & PM9 & 0.757 & & & \\
\hline \multirow[t]{6}{*}{ Emotional intelligence } & & & 0.81 & 0.863 & 0.513 \\
\hline & EI1 & 0.789 & & & \\
\hline & EI11 & 0.659 & & & \\
\hline & EI12 & 0.69 & & & \\
\hline & EI2 & 0.745 & & & \\
\hline & EI3 & 0.71 & & & \\
\hline
\end{tabular}




\begin{tabular}{|l|l|r|l|l|l|}
\hline & EI5 & 0.696 & & & \\
\hline & & & 0.773 & 0.775 & 0.556 \\
\hline & CS1 & 0.89 & & & \\
\hline & CS2 & 0.405 & & & \\
\hline & CS3 & 0.845 & & & \\
\hline
\end{tabular}

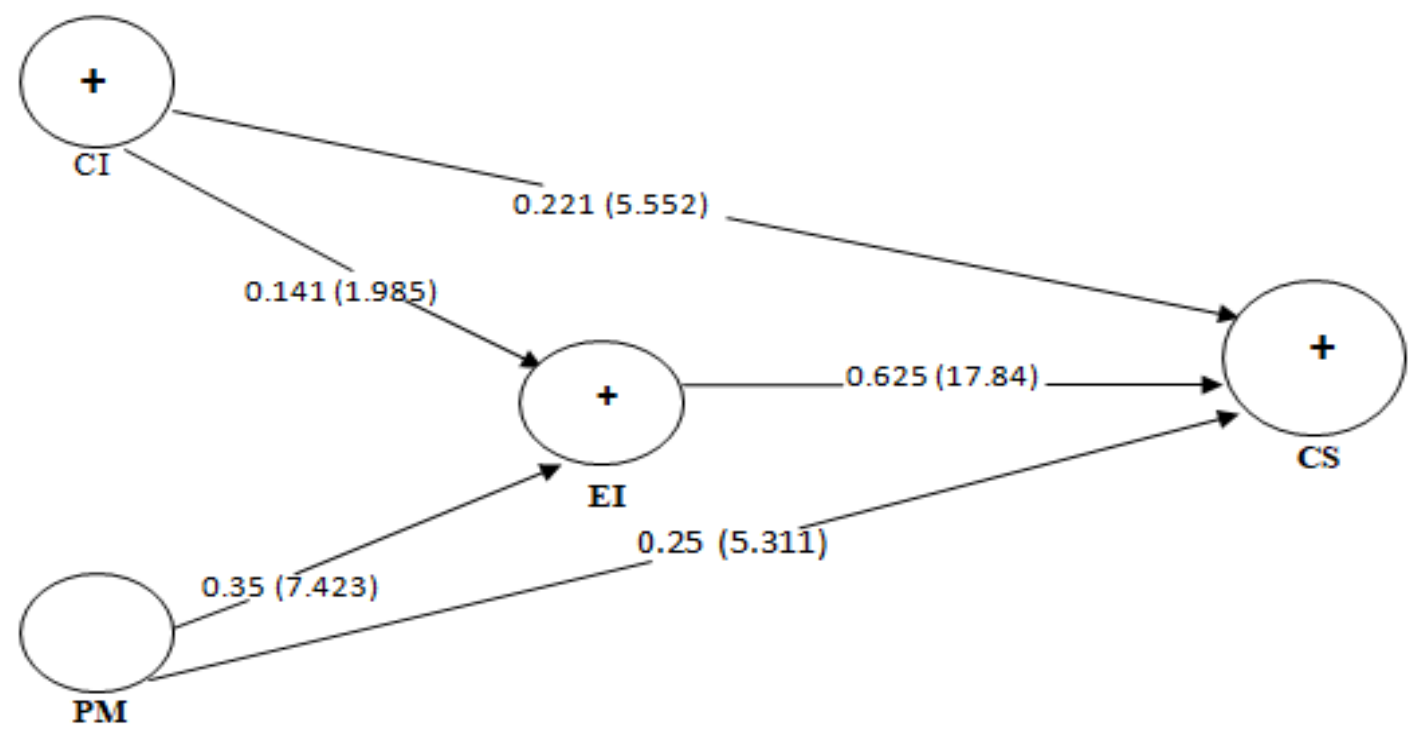

Fig 2: Confirmatory factor analysis

\subsection{Discriminant validity}

As per Kock, (2011). "a measurement instrument has good discriminant validity if the questionstatements associated with each LV are not confused by the respondents to the questionnaire with the question-statements associated with other LVs, particularly in terms of the meaning of the questionstatements".

In table 2 the diagonal, result displays the square root of AVE of all variables. All the square roots of AVE of all the variables are bigger than the off-diagonal elements, hereafter an indication of discriminant validity is determined.

Table 2: Hetrotrait-Monotrait Ratio

\begin{tabular}{|c|c|c|c|c|}
\hline Variables & CS & EI & PM & CI \\
\hline CS & $\mathbf{0 . 7 4 6}$ & & & \\
\hline EI & 0.63 & $\mathbf{0 . 7 1 6}$ & & \\
\hline PM & 0.648 & 0.673 & $\mathbf{0 . 7 4 2}$ & \\
\hline CI & 0.508 & 0.525 & 0.72 & $\mathbf{0 . 7 5 4}$ \\
\hline
\end{tabular}

\subsection{Assessment of Structural Model (Stage Two)}

Second stage is to examine the proposed structural model. In this study PLS has been used to test the hypothesis. 5000 Bootstrapping was run to check the significant values to decide whether hypothesis is supported or not. In order to analyze whether to we reject the null hypothesis, T-value and P-value were carefully analyzed. Effects indicates all hypotheses are significant and supported by results. 


\subsection{Direct Effects}

SEM PLS structural model analysis was conducted to comprehend the relationships within the constructs. Implication of path coefficients was calculated by using bootstrapping .H1a foretold an effect of compensation \& incentive on emotional intelligence. There was a substantial positive impact of compensation \& incentive on emotional intelligence $(\beta=0.141, t=1.985)$, hereafter hypothesis H1a is supported. That means that if compensation \& incentive offered to employees the emotional intelligence of employees will also upturn. Hypothesis $\mathrm{H1b}$ foretold an effect of performance management on emotional intelligence. A significant positive effect of performance management on emotional intelligence appeared $(\beta=0.35, \mathrm{t}=7.423)$, in this way $\mathrm{H} 1 \mathrm{~b}$ is also sustained. This means that efficient performance management system will outpouring the emotional intelligence of employees. $\mathrm{H} 2 \mathrm{forecast}$ influence of emotional intelligence on customer satisfaction. There was a substantial positive impact of emotional intelligence on customer satisfaction $(\beta=0.625, \mathrm{t}=17.84)$, in this way $\mathrm{H} 2$ is reinforced. That means that when employees are emotionally intelligent it will surge the customer satisfaction. H3a foretold impact of compensation \& incentive on customer satisfaction. There was a substantial positive impact of compensation \& incentive on customer satisfaction $(\beta=0.221, t=5.552)$, H3a is confirmed. . This means that efficient compensation and incentive system will flood the customer satisfaction. $\mathrm{H} 3 \mathrm{~b}$ determined an impact of performance management on customer satisfaction. There was a substantial positive impact of performance management on customer satisfaction $(\beta=0.25, \mathrm{t}=$ 5.311), $\mathrm{H} 3 \mathrm{~b}$ is approved. It means that efficient performance management system will spate the customer satisfaction.

Table 3: Path modeling

\begin{tabular}{|c|c|c|c|c|c|}
\hline Hypothesis & Relationship & Std. Beta & S.E. & t-Value & Decision \\
\hline H1a & CI -> EI & 0.141 & 0.071 & 1.985 & Supported \\
\hline H1b & PM - EI & 0.35 & 0.05 & 7.423 & Supported \\
\hline H2 & EI -> CS & 0.625 & 0.047 & 17.84 & Supported \\
\hline H3a & CI -> CS & 0.221 & 0.04 & 5.552 & Supported \\
\hline H3b & PM -> CS & 0.25 & 0.059 & 5.311 & Supported \\
\hline
\end{tabular}

\subsection{Mediation results}

Hypothesis H4a with indirect effect CI -> EI -> CS was found as significant $(\beta=0.03, \mathrm{t}=1.875)$. The indirect effects 95\% Boot CI [LL $=0.004$, UL $=0.104]$, did not span $\mathrm{o}$ among confirming the mediation. In current study emotional intelligence interact as mediator among compensation \& incentive and customer satisfaction. Table 4 shows $\mathrm{H}_{4} \mathrm{a}$ is supported. It can be confirmed that emotional intelligence mediates relation of compensation \& incentive on customer satisfaction. $44 \mathrm{~b}$ with an indirect impact PM -> EI $->$ CS was significant $(\beta=0.215, \mathrm{t}=6.588$ with $[\mathrm{LL}=0.16, \mathrm{UL}=0.287$, so mediation was confirmed. In existing study emotional intelligence interact as mediator among performance management and customer satisfaction. Table 4 shows $\mathrm{H} 4 \mathrm{~b}$ is supported .Therefore emotional intelligence mediates impacts of performance management on customer satisfaction.

Table 4: Results of Mediation

\begin{tabular}{|l|c|c|c|c|c|c|c|}
\hline H & Link & $\begin{array}{c}\text { Std. } \\
\text { beta }\end{array}$ & $\begin{array}{c}\text { Std. } \\
\text { error }\end{array}$ & T Stat & LL & UL & Conclusion \\
\hline $\mathrm{H} 4 \mathrm{a}$ & $\mathrm{CI}->\mathrm{EI}->\mathrm{CS}$ & 0.03 & 0.016 & 1.875 & 0.004 & 0.104 & Supported \\
\hline $\mathrm{H} 4 \mathrm{~b}$ & $\mathrm{PM}->\mathrm{EI}->\mathrm{CS}$ & 0.215 & 0.033 & 6.588 & 0.16 & 0.287 & Supported \\
\hline
\end{tabular}




\section{Discussion}

This study adds to arena of customer services by establishing empirically proved relationship between motivation-enhancing practices, emotional intelligence and customer satisfaction. The results highlight that motivation-enhancing HR practices were perceived a significant cause of 'emotional intelligence'. In those organizations which deal with customer services, motivation-enhancing HR practices deliberate to ensure that employees take emotional abilities as mandatory.

Performance management, compensation, and incentive systems have been considered as predictors of enhancing motivation amongst the employees at workplace (Jiang, Lepak, Hu, et al., 2012). The research has found the positive relationship of incentives for emotional displays with employees' dedication and motivation to follow the display rules (Diefendorff \& Croyle, 2008).Performance based rewards are likely to act more stronger in terms of expectation and anticipation in the scenario where HR practices like incentives or reward for performance are applicable (Fang \& Gerhart, 2012).It is so because these reward expectations have tendency to enhance the performance attitude (Jenkins, Mitra, Gupta, \& Shaw, 1998). Monitoring has positive relationship with well-being of employees irrespective of the fact that it was aimed for development objectives or merely for performance evaluation (Holman et al., 2002). It has also been argued that performance monitoring provides comparatively a true picture of performance than the annually conducted performance appraisals of employees (e.g., Grant \& Higgins, 1989).

In the setting of this research, employees' emotional intelligence increases customer satisfaction. Emotional performance is defined as appearance of behaviors reflected through attitude is an insightful of set patterns of organizations (Hu“lsheger\&Schewe 2011), which are generally measured as fundamental antecedents of service industry (Diefendorff et al. 2006).Usually, high emotional display is an indicator of improved customer satisfaction and 'intention to return' ( Barger \&Grandey 2006). Simple gestures like passing smile, eyes contact and a polite verbal tone are essentials of satisfaction of the consumers (Barger \&Grandey 2006). Researchers detected that dealings the consumers with smile in a delivery process in the services, caused the satisfaction level of the customers. Gabriel, Acosta, et al. (2015) found that smile and positive body language in terms of eye contact and pitch of voice are the ingredients of positive presentation having influences on customers through the feelings of satisfaction.

Expectancy of good impacts of positive 'emotional display' of employees is expected through marketing in the area of service quality. The researchers determined that measuring the service quality means matching expected image with perceiving real one (Parasuraman, Zeithaml\&Berry, 1985).

In this study, motivation-enhancing HR practices created an independent variable, and its indirect effect on 'customer satisfaction' was executed through emotional intelligence. As the service industry unceasingly grows (Henderson, 2012), for this organizations face the challenge to guarantee outstanding services for customers (Liao \& Chuang, 2007). For this encounter, organizations depends on 'front-line employees' to provide services pleasantly with smile by application of 'emotional labor' for fixing their emotions to cope with expectations of 'emotional display' (Hochschild, 1983). Subsequently that may affect the consumers' targets in a positive manner (Grandey, 200o). The researchers (Pugh, Diefendorff, and Moran,2013) recommended ways to achieve 'emotional labor' by executing 'HR practices', for example training of employees so that their emotional behavior is displayed.

Research in past established the relationship of 'emotional intelligence' with customer satisfaction (Gabriel, Acosta, \&Grandey, 2015). After deliberating this significance with reference to 
customer service, however the extended work to regulate the capabilities of employees still lacks. Although Chen and Lin (2009) did struggle to validate how HR- policies can reduce emotionally exhaustion; it is yet a beginning to voyage the wider canvass of emotional labor.

\section{Contribution of the study}

There are many reasons why this study is unique in nature. Motivation enhancing HR practices of AMO framework have been linked with customer satisfaction in banking sector of Punjab, Pakistan, mediated through emotional intelligence of employees of the banks. This proposition has been tested in this research and there is strong logic based on statistical results that emotional intelligence mediated this relationship in the banking sector. Paradigm shift in economic activities pursuing a customer oriented theory has greatly affected the banking sector like many other business sectors (Grigoroudis, Politis, \&Siskos, 2002).

\section{Directions for Future Research}

In future researchers may examine different variables targeting the increased variance clarified through this model. Furthermore, they might deliberate on particular circumstances that may show customer service outcomes as more or less operative. Future studies can examine other self-regulation strategies as a mediating variable. Likewise, this study advises future studies to examine employees' engagement as moderating variable.

\section{Conclusion}

This study complement to an assimilated model which relates emotional intelligence to motivation-enhancing HR practices. Furthermore the research indicates the value and practicality of emotional intelligence through empirically tested investigation showing its link with customer satisfaction. In view of above results, there is adequate indication that the culture of 'HRM practices' functioning in bundles in banking sector may perform a conclusive part for improving emotional intelligence (EI) of the employees. The conclusions of study provide decisive empirical evidence that emotional intelligence (EI) of employees is one of basic factors of organizational success. We may reasonably conclude that organizations generally and banking sector in particular can derive sizeable benefits by ensuring employees deepened in emotional intelligence. This study delivers a deep vision on how CS can be improved in the banking sector effectively.

\section{References}

Barger, P. B., \& Grandey, A. A. (2006). Service with a smile and encounter satisfaction: Emotional contagion and appraisal mechanisms. Academy of management journal, 49(6), 1229-1238.

Bigné, J. E., Andreu, L., \& Gnoth, J. (2005). The theme park experience: Analysis of pleasure, arousal and satisfaction. Tourism Management, 26, 833-844.

Bitner, M. J., \& Wang, H. S. (2014). 11. Service encounters in service marketing research. Handbook of service marketing research, 221

Borucki, C. C., \& Burke, M. J. (1999). An examination of service-related antecedents to retail store performance. Journal of organizational Behavior, 943-962.

Byrne, B. M. (2013). Structural equation modeling with LISREL, PRELIS, and SIMPLIS: Basic concepts, applications, and programming. Psychology Press.

Chen, C. and Huang, J. (2009), Strategic human resource practices and innovative performance: the mediating role of knowledge management capacity, Journal of Business Research, 62, 104-114

Chen, L.H., \& Lin, S.P. (2009).Reducing service agents' emotional labor by emotion-focused human resource management practices. Social Behavior and Personality: An International Journal, 37, 
335-341.

Chin, W. W. (1998). Issues and opinion on structural equation modeling. MIS Quarterly, 22(1), 7-16.

Colgate, M. R., \& Danaher, P. J. (2000).Implementing a customer relationship strategy: The asymmetric impact of poor versus excellent execution. Journal of the Academy of Marketing Science, 28, $375-387$.

Deshpandé, R., Farley, J. U., \& Webster, F. E. (1993). Corporate culture, customer orientation and innovativeness in Japanese firms: a quadrat analysis. Journal of Marketing, 57(1), 23-37.

Diefendorff, J. M., Richard, E. M., \& Croyle, M. H. (2006). Are emotional display rules formal job requirements? Examination of employee and supervisor perceptions. Journal of Occupational and Organizational Psychology, 79(2), 273-298.

Diefendorff, J.M., \& Croyle, M.H. (2008). Antecedents of emotional display rule commitment. Human Performance, 21, 310-332.

Fang M, Gerhart B. (2012). Does pay for performance diminish intrinsic interest?. The International Journal of Human Resource Management, 23, 1176-1196.

Gabriel, A. S., Acosta, J. D., \& Grandey, A. A. (2015). The value of a smile: does emotional performance matter more in familiar or unfamiliar exchanges?. Journal of Business and Psychology, 30(1), 3750.

Giardini, A., \& Frese, M. (2006). Reducing the negative effects of emotion work in service occupations: emotional competence as a psychological resource. Journal of Occupational Health Psychology, $11(1), 63$.

Glomb, T.M., Kammeyer-Mueller, J.D., \& Rotundo, M. (2004).Emotional labor demands and compensating wage differentials. Journal of Applied Psychology, 89,700-714.

Grandey, A. (2000). Emotion regulation in the workplace: A new way to conceptualize emotional labor. Journal of Occupational Health Psychology, 5, 95-110.

Grandey, A. (2000). Emotion regulation in the workplace: A new way to conceptualize emotional labor. Journal of Occupational Health Psychology, 5, 95-110.

Grandey, A. A., \& Gabriel, A. S. (2015). Emotional labor at a crossroads: Where do we go from here? Annual Review of Organizational Psychology and Organizational Behavior, 2, 323-349.

Grandey, A. A., Chi, N. W., \& Diamond, J. A. (2013). Show me the money! Do financial rewards for performance enhance or undermine the satisfaction from emotional labor?. Personnel Psychology, 66(3), 569-612.

Grant, R., \& Higgins, C. (1989).Monitoring service workers via computer: The effect on employees, productivity, and service. National Productivity Review, 8, 101-112.

Grant, R., \& Higgins, C. (1989).Monitoring service workers via computer: The effect on employees, productivity, and service. National Productivity Review, 8, 101-112.

Grigoroudis, E., Politis, Y., \& Siskos, Y. (2002). Satisfaction benchmarking and customer classification: An application to the branches of a banking organization. International transactions in operational research, 9(5), 599-618.

Gustafsson, A., \& Johnson, M. D. (2004). Determining attribute importance in a service satisfaction model. Journal of Service Research, 7(2), 124-141.

Gutek, B. A. (1995). The dynamics of service: Reflections on the changing nature of customer/provider interactions. Jossey-Bass.

Gwinner, K. P., Gremler, D. D., \& Bitner, M. J. (1998). Relational benefits in service industries: The customer's perspective. Journal of the Academy of Marketing Science, 26, 101-114.

Hair, J. F., Black, W. C., Babin, B. J., \& Anderson, R. E. (2010).Multivariate data analysis: A global perspective (7th ed.). Upper Saddle River, NJ: Pearson-Prentice Hall.

Hartline, M. D., Maxham III, J. G., \& McKee, D. O. (2000). Corridors of influence in the dissemination of customer-oriented strategy to customer contact service employees. Journal of Marketing, 64(2), 
35-50.

Henderson, R. (2012). Industry employment and output projections to 2020. Monthly Labor Review, $135,65-83$.

Hochschild, A.R. (1983). The Managed Heart: The Commercialization of Feeling. Berkeley, CA: University of California Press.

Hochschild, A.R. (1983). The Managed Heart: The Commercialization of Feeling. Berkeley, CA: University of California Press.

Holman, D., Chissick, C., \& Totterdell, P. (2002). The effects of performance monitoring on emotional labor and well-being in call centers. Motivation and Emotion, 26(1), 57-81.

Hülsheger, U. R., \& Schewe, A. F. (2011). On the costs and benefits of emotional labor: a meta-analysis of three decades of research. Journal of occupational health psychology, 16(3), 361.

Hunt, H. K. (1993). CSD\&CB Research Suggestions and Observations for the 1990's. Journal of Consumer Satisfaction, Dissatisfaction and Complaining Behavior, 6, 40-42.

Islam N. (2005), 'Sifarish, Sycophants, Power and Collectivism: Administrative Culture in Pakistan', Internat io nal Review of Administrative Sciences, Vol. 70, No. 2, pp.311-330.

Jenkins Jr, G. D., Mitra, A., Gupta, N., \& Shaw, J. D. (1998). Are financial incentives related to performance? A meta-analytic review of empirical research.

Jiang, K., Lepak, D. P., Hu, J., \& Baer, J. C. (2012). How does human resource management influence organizational outcomes? A meta-analytic investigation of mediating mechanisms. Academy of management Journal, 55(6), 1264-1294.

Jiang, K., Lepak, D.P., Han, K., Hong, Y., Kim, A., \&Winkler, A.L. (2012). Clarifying the construct of human resource systems: Relating human resource management to employee performance. Human Resource Management Review, 22, 73-85.

Joseph DL, Newman DA. 2010. Emotional intelligence: an integrative meta-analysis and cascading model. Journal of Applied Psychology. 95(1):54-78

Kazi, M. (2003). Realist evaluation for practice. British journal of social work, 33(6), 803-818.

Khan, M. M., \& Fasih, M. (2014). Impact of service quality on customer satisfaction and customer loyalty: Evidence from banking sector. Pakistan Journal of Commerce and Social Sciences, 8(2), 331-354.

Kock, N. (2011). Using WarpPLS in E-Collaboration Studies: descriptive Statistics, Settings, And Key Results. IJeC, 7, 1-18.

Law, K. S., Wong, C. S., \& Song, L. J. (2004). The construct and criterion validity of emotional intelligence and its potential utility for management studies. Journal of applied Psychology, $89(3), 483$.

Lemon, K. N., \& Verhoef, P. C. (2016). Understanding customer experience throughout the customer journey. Journal of marketing, 8o(6), 69-96.

Liao, H., \& Chuang, A. (2004).A multilevel investigation of factors influencing employee service performance and customer outcomes.Academy of Management Journal, 47, 41-58.

Liao, H., \& Chuang, A. (2007). Transforming service employees and climate: a multilevel, multisource examination of transformational leadership in building long-term service relationships. Journal of Applied Psychology, 92, 1006-1019.

Maxham III, J. G., \& Netemeyer, R. G. (2002). A longitudinal study of complaining customers' evaluations of multiple service failures and recovery efforts. Journal of marketing, 66(4), 57-71.

Naeem, H., Akram, A., \& Saif, M. I. (2011). Service Quality and its impact on Customer Satisfaction: An empirical evidence from the Pakistani banking sector. International Business \& Economics Research Journal (IBER), 8(12).

Parasuraman, A., Zeithaml, V. A., \& Berry, L. L. (1985).A conceptual model of service quality and its implications for future research. The Journal of Marketing, 41-50. 
Poster,W.R. (2011). Emotion detectors, answering machines, and e-unions:Multi-surveillances in the global interactive service industry. American Behavioral Scientist,55, 868-901.

Preacher, K. J., \& Hayes, A. F. (2004). SPSS and SAS procedures for estimating indirect effects in simple mediation models. Behavior Research Methods, Instruments, \& Computers, 36(4), 717-731.

Pugh, S. D., Diefendorff, J. M., \& Moran, C. M. (2013). Emotional labor: Organization-level influences, strategies, and outcomes. Routledge/Taylor \& Francis Group.

Ringle, C. M., Wende, S., \& Will, A. (2005). Smart PLS 2.o. Software download from www.smartpls.de

Ringle, C. M., Wende, S., \& Will, A. (2005). SmartPLS 2.o. Software download from www.smartpls.de

Sharma, N. P., Sharma, T., \& Agarwal, M. N. (2016). Measuring employee perception of performance management system effectiveness: Conceptualization and scale development. Employee Relations.

Solomon, M. R., Surprenant, C., Czepiel, J. A., \& Gutman, E. G. (1985). A role theory perspective on dyadic interactions: the service encounter. The Journal of Marketing, 99-111.

Straub, D., Boudreau, M. C., \&Gefen, D. (2004). Validation guidelines for IS positivist research. The Communications of the Association for Information Systems, 13(1), 63.

Ulrich, D., Halbrook, R., Meder, D., Stuchlik, M., \& Thorpe, S. (1991). Employee and customer attachments: Synergies for competitive advantage. Human Resource Planning, 14(2), 89-104.

Voorhees, C., Fombelle, P., Allen, A. M., Bone, S. A., \& Aach, J. (2014). Managing post purchase moments of truth: Leveraging customer feedback to increase loyalty. Marketing Science Institute Reports, 14-115.

Wamboye, E. F., \& Nyaronga, P. J. (2018). A comparative analysis of gendered labour market outcome in Africa and Asia's least developed countries. In The Service Sector and Economic Development in Africa (pp. 145-156). Routledge.

Wamboye, E. F., \& Nyaronga, P. J. (2018). The Service Sector and Economic Development in Africa. Routledge.

Wei, Y. C., Han, T. S., \& Hsu, I. C. (2010). High-performance HR practices and OCB: A cross-level investigation of a causal path. The International Journal of Human Resource Management, 21(10), 1631-1648.

Wiley, J. W. (1996). Linking survey results to customer satisfaction and business performance. Organizational surveys: Tools for assessment and change, 330-359.

Zerbe, W. J., Dobni, D., \& Harel, G. H. (1998). Promoting employee service behavior: The role of perceptions of human resource management practices and service culture. Canadian Journal of Administrative Sciences, 15(2), 165-179. 